J. Lake Sci.(湖泊科学), 2017, 29(1): 116-126

DOI 10. 18307/2017. 0113

(c) 2017 by Journal of Lake Sciences

\title{
三峡澎溪河高阳平湖碳通量初步分析及不确定性“
}

\author{
徐琳琳 ${ }^{1,2}$, 李 哲 ${ }^{2,3 * *}$, 李 羽 $^{3}$, 陈永柏 ${ }^{3}$, 郭劲松 ${ }^{2}$, 肖 艳 ${ }^{2}$ \\ ( 1 : 重庆大学城市建设与环境工程学院, 重庆 400044) \\ (2: 中国科学院重庆绿色智能技术研究院水库水环境重点实验室,重庆 400714) \\ (3: 中国长江三峡集团, 北京 100038)
}

摘 要: 为明确三峡水库支流澎溪河回水区的碳收支特征, 以澎溪河高阳平湖水域为研究对象, 建立了河道型水库主要 路径碳收支估算方法, 对高阳平湖从 2011 年 9 月至 2012 年 8 月一个完整水文周年内主要路径的碳通量进行了收支动态 分析. 结果表明, 2011 年 9 月至 2012 年 8 月,澎溪河高阳平湖水域河流输人的碳通量为 $133548.55 \mathrm{tC}$, 输出的碳通量为 $125651.82 \mathrm{t} \mathrm{C}$, 水一气界面的扩散碳通量为 $762.56 \mathrm{t} \mathrm{C}$, 消落带土一气界面的扩散碳通量为 $123.74 \mathrm{t} \mathrm{C}$, 水中气泡的释放碳通 量为 $0.38 \mathrm{t} \mathrm{C}$, 降水输人的碳通量为 $104.58 \mathrm{t} \mathrm{C}$, 全年高阳平湖水域碳的净积累量为 $7114.63 \mathrm{t} \mathrm{C}$, 宏观上呈现碳积累特征; 澎溪河高阳平湖水域水体碳素总体上呈现出河道型水库特有的纵向输移特征. 高阳平湖水域上游大量碳素的输人及其 在高阳平湖水域的滞留可能会是该水域水一气界面温室气体释放的主要来源. 尽管总体上高阳平湖全年呈现出碳积累的 特点,但一些方法依然存在不确定性 (水一气界面扩散碳通量和气泡释放碳通量的时空异质性等), 需要更系统、更长期 的工作予以验证或改进.

关键词: 三峡水库;澎溪河;高阳平湖;碳;空间分布;收支动态

\section{A preliminary study of carbon balance and the uncertainty for Lake Gaoyang, Pengxi Riv- er of the Three Gorges Reservoir}

\author{
XU Linlin ${ }^{1,2}$, LI Zhe ${ }^{2,3 * *}$, LI Chong ${ }^{3}$, CHEN Yongbo ${ }^{3}$, GUO Jinsong ${ }^{2} \&$ XIAO Yan ${ }^{2}$ \\ (1: Faculty of Urban Construction and Environmental Engineering, Chongqing University, Chongqing 400044, P.R.China) \\ (2: Key Lab of Reservoir Water Environment, Chongqing Institute of Green and Intelligent Technology, Chinese Academy of \\ Sciences, Chongqing 400714, P.R.China) \\ (3: China Three Gorges Corporation, Beijing 100038, P.R.China)
}

\begin{abstract}
To understanding the carbon budget, our research chose Lake Gaoyang as object and established an estimate method of carbon budget. From September 2011 to August 2012, we analyzed the main path of carbon budget for the Lake Gaoyang in Pengxi River. The main conclusions for the one year are as follows: input carbon fluxes of river transport were $133548.55 \mathrm{t}$, output carbon fluxes of river transport were $125651.82 \mathrm{t} \mathrm{C}$, diffusive fluxes of water to air interface were $762.56 \mathrm{t} \mathrm{C}$, diffusive fluxes of waterlevel-fluctuating zone were $123.74 \mathrm{t}$ C, ebullition fluxes were $0.38 \mathrm{t} \mathrm{C}$, input carbon fluxes of precipitation were $104.58 \mathrm{t} \mathrm{C}$, and net accumulation of carbon fluxes of the Lake Gaoyang were 7114.63 t C. It was mainly in the form of dissolved inorganic carbon. The carbon in the water of the Lake Gaoyang in Pengxi River showed the characteristics of longitudinal transport along the river channel. Lots of carbon went into the uplift air and deposited in Lake Gaoyang from upstream. It may be the main source of greenhouse gases on the water to air interface. As a whole, Lake Gaoyang presents the characteristic of carbon accumulation throughout the year, but some methods remains uncertain for the spatial and temporal heterogeneity of water-gas interface diffusion flux and air release flux. We need more systematic and long-term work to verify or modify.
\end{abstract}

Keywords: Three Gorges Reservoir; Pengxi River; Lake Gaoyang; carbon; spatial distribution; budget

* 国家自然科学基金项目 (51679226) 和重庆市基础科学和前沿技术研究重点项目 (CSTC2015JCYJBX0006) 联合资 助. 2015-06-11 收稿; $2016-06-09$ 收修改稿. 徐琳琳 (1989 ), 女, 硕士研究生; E-mail : xulinlin0707@ 163.com.

** 通信作者;E-mail: ZheLi81@ sina.com. 
河流通常是水体碳素在陆地生态系统和海洋间的转换过渡区域, 其输送的溶解态物质和颗粒态物质占 陆地向边缘海洋传输量的 $90 \%$, 在全球碳循环中有着举足轻重的作用 ${ }^{[1-3]}$. 筑坝蓄水对河流碳输送产生了显 著影响, 是近年来全球变化研究的热点之一 ${ }^{[4-5]}$. 尽管如此, 目前对水库碳收支的研究依然有限, 大部分研究 以湖泊为对象开展. Hope 等在研究美国威斯康辛州 27 个湖泊中发现湖泊水体中的 $\mathrm{CO}_{2}$ 含量与流域及湖泊 面积的比值有明显的正相关关系, 说明流域输人是湖泊水体中碳素的主要来源 ${ }^{\left[{ }^{8]}\right.}$. Richey 等对湖泊系统的 碳路径进行了研究, 发现湖泊除了从地表径流和地下水源获得碳以外, 同时还能从上空物质中获得碳 ${ }^{[9-10]}$. Keller 等在对 Gatun 水库进行研究时发现, 以气泡释放形式扩散的 $\mathrm{CO}_{2}$ 和 $\mathrm{CH}_{4}$ 通量范围分别为 $500 \sim 1000$ 和 $5 \sim 10 \mathrm{mg} /\left(\mathrm{m}^{2} \cdot \mathrm{d}\right)^{[11]}$. Duchemin 等对加拿大寒带地区水库的温室气体释放通量进行了为期两年的研究, 横 向对比了水库温室气体的监测方法, 并通过对水库的长年跟踪监测, 构建了水库温室气体的估算评价体 系 ${ }^{[12]}$. 秡晓燕等利用静态箱法对太湖地区四季的水一气界面 $\mathrm{CO}_{2}$ 通量的季节变化特征进行了研究 ${ }^{[13]}$.

目前国内研究大多只关注水库水-气界面 $\mathrm{CO}_{2}$ 和 $\mathrm{CH}_{4}$ 温室气体的通量特征, 或从某单一方面研究温室气 体的通量. 从水库关键界面碳通量和碳收支的角度来揭示筑坝蓄水对碳生物地球化学过程的影响, 目前鲜 有报道. 本研究以三峡水库典型支流澎溪河高阳平湖水域为研究对象, 在高阳平湖关键界面碳通量观测基 础上, 对其碳收支进行初步分析, 研究将为下一阶段开展水库碳循环模型研究奠定前期基础.

\section{1 材料与方法}

高阳平湖水域 (图 1) 地处澎溪河下游永久回水区中部, 具有类似湖泊的地貌环境及水文水力特征. 受 水库运行影响, 在三峡水库季节性水位涨落下呈现出 “浅水湖泊-深水湖泊” 的交替变化特征, 在库区中段支 流回水区或库湾中具有典型性和代表性. 研究时间为一个完整水文周年(2011 年 9 月-2012 年 8 月), 共设 置高阳平湖人口、湖心、出口、库湾平台 (含消落带) 4 个采样点 (图 2), 逐月开展跟踪观测.

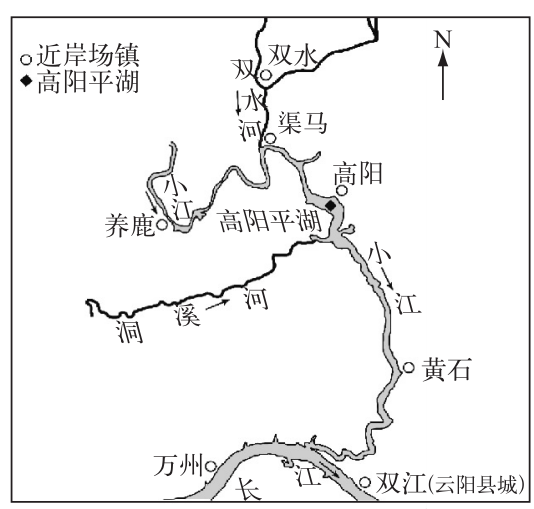

图 1 澎溪河高阳平湖位置

Fig. 1 Backwater area of

Pengxi River and Lake Gaoyang

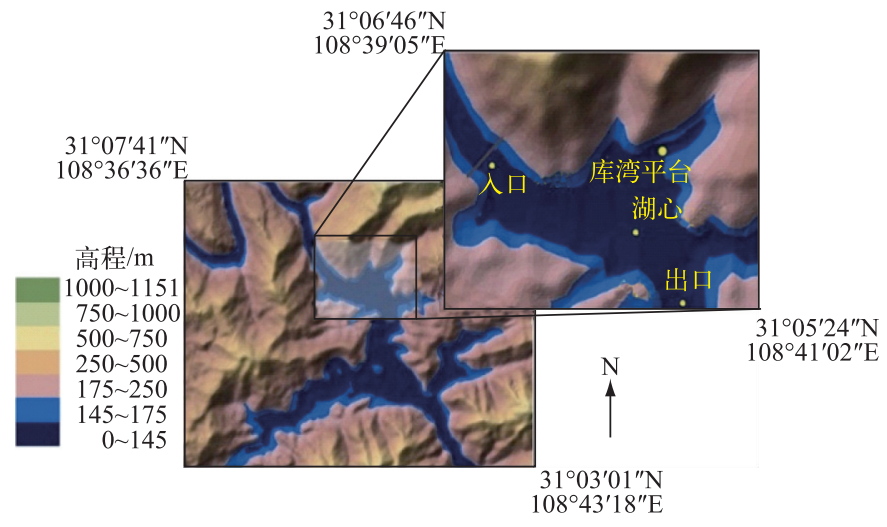

图 2 高阳平湖采样点位置

Fig. 2 Location of sampling sites in Lake Gaoyang

从水库生态系统外部来看, 水体碳素的迁移过程主要包括河流输送、水一气界面气体扩散、土一气界面气 体扩散、气泡释放以及降水输送等(图 3). 作为一个独立的系统, 本研究着重考虑了出入系统各关键界面的 碳通量情况,而关于系统内部的一些过程则并不予考虑, 主要原因有以下几个方面:

1) 藻类初级生产 (光合固碳) 和细菌降解作用 (好氧产生 $\mathrm{CO}_{2}$ 、厌氧产生 $\mathrm{CH}_{4}$ ), 均将调节改变水体中的 $\mathrm{CO}_{2}$ 或 $\mathrm{CH}_{4}$ 浓度, 并最终通过水一气界面气体交换予以实现. 水-气界面静态箱法所测试的 $\mathrm{CO}_{2}$ 和 $\mathrm{CH}_{4}$ 通量值 (正值代表水体向大气释放; 负值代表水体从大气吸收), 既包含了藻类光合呼吸导致的 $\mathrm{CO}_{2}$ 吸收, 也包括了 水体中因细菌降解等向大气释放的 $\mathrm{CO}_{2}$ 和 $\mathrm{CH}_{4}$. 不仅是水体中 $\mathrm{CO}_{2}$ 和 $\mathrm{CH}_{4}$ 源、汇 “双向” 过程汇总后的一个表 观结果, 也是水体和大气中 $\mathrm{CO}_{2} 、 \mathrm{CH}_{4}$ 浓度相互关系的表现. 
2) 本研究中测试的河流输人、输出部分, 包含了泥沙的输人、输出, 关于泥沙 (含碳) 在高阳平湖内沉积, 研究认为该部分属于系统内部碳在高阳平湖中积累的结果.

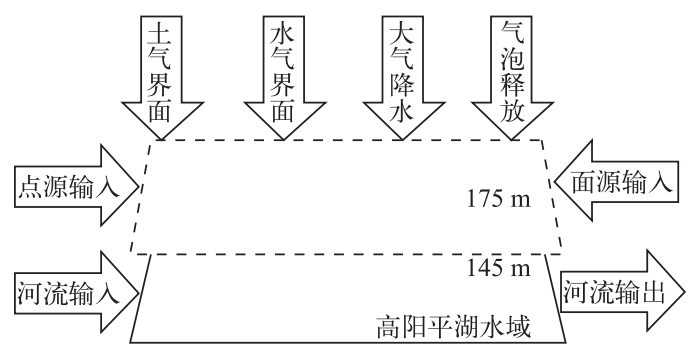

图 3 高阳平湖水域水体碳素迁移过程示意

Fig.3 Sketch of water carbon migration process of Lake Gaoyang

进一步将该收支方案进行概化或简化:

1) 高阳平湖控制断面 (高阳平湖人口至其出口断面) 水域面积大约为 $3 \sim 4 \mathrm{~km}^{2}$, 近岸高阳镇场镇污水收 集后排至该水域下游. 故在对高阳平湖碳收支的初步估算中, 近岸场镇点源对该水域的碳输人可忽略不计.

2) 高阳平湖为典型的过水型湖泊, 其控制断面的流域面积仅为 $5 \sim 6 \mathrm{~km}^{2}$, 流域面积相对较小, 沿岸并无 大面积农田耕作, 且空间边界为 $175 \mathrm{~m}$ 水位线 (包含了低水位运行期时消落带所带来的碳输人), 因此研究 认为相对于河流纵向输送, $175 \mathrm{~m}$ 水位线以上区域的面源所带来的碳输人可忽略. 故对高阳平湖碳收支的初 步估算中,暂不涉及面源所带来的碳输人.

3) 本研究对消落带土一气界面进行了监测, 但消落带在裸露期间可能因陆生植被恢复出现碳汇, 植被在 受淹后可能被降解, 对水-气界面 $\mathrm{CO}_{2} 、 \mathrm{CH}_{4}$ 通量有所贡献. 受实验条件所限, 因植被恢复期间出现碳汇部分 并未予以考虑. 而植被受淹后可能降解并对水一气界面 $\mathrm{CO}_{2} 、 \mathrm{CH}_{4}$ 的贡献量研究认为已经隐含在水-气界面 $\mathrm{CO}_{2} 、 \mathrm{CH}_{4}$ 的监测结果中,故并不予以额外单独计算.

故主要针对上述 5 个主要碳路径对高阳平湖水域进行碳收支估算和分析.

现场测试分析指标包括: 采用 $\mathrm{YSI}^{\odot} 63$ 型 $\mathrm{pH}$ 测量仪测定水体 $\mathrm{pH}$ 值 (精度 0.01 个 $\mathrm{pH}$ ); 采用 YSIProODO 溶解氧仪测定水温及溶解氧 ( DO) (精度分别为 $0.1^{\circ} \mathrm{C}$ 和 $0.01 \mathrm{mg} / \mathrm{L}$ ) ; 碱度 $(\mathrm{TA}$ ) 采用 $\mathrm{HACH}$ 公司 的微量滴定器及标准硫酸溶液现场滴定 (精度为 $1.25 \mu \mathrm{l}$ ) ; 现场还测定风速、气温等. 现场采样结束后, 将各 断面水样带回实验室于 $48 \mathrm{~h}$ 内完成其他指标的分析测试工作.

\section{1 河流输送碳通量}

将高阳平湖水域看作一个整体, 水体碳素的河流输送包括河流输人和河流输出两条路径. 上游水体中 的碳素通过河流输人进入高阳平湖, 高阳平湖中的碳素又通过河流输出流向下游, 两者的差值即为高阳平 湖水域在河流输送过程中输人或输出的水体碳素通量. 通过公式计算, 即可估算出高阳平湖水域每个月河 流输送过程中所产生的碳通量. 本研究中, 高阳平湖人口和出口采样点均设置 3 个平行采样断面, 每个月的 采样深度根据实际水深而确定, 对各采样深度水样进行等量混合后完成测试工作, 然后取 3 个平行断面的 平均值作为河流输送和输出碳通量.

$$
G_{1}=86400 Q_{1} \cdot C_{1} \cdot t
$$

式中, $G_{1}$ 为河流输送碳通量 $(\mathrm{g}), Q_{1}$ 为河流流量 $\left(\mathrm{m}^{3} / \mathrm{s}\right), C_{1}$ 为水体碳素平均浓度 $(\mathrm{mg} / \mathrm{L}), t$ 为采样月份的天 数 (d).

河流输人、输出中的总碳量等于溶解性无机碳 ( DIC) 、溶解性有机碳 (DOC) 和颗粒态碳 $(P C)$ 三者之和 (即: $: \mathrm{TC}=\mathrm{DIC}+\mathrm{DOC}+\mathrm{PC})$. DIC 浓度现场滴定, DOC 浓度采用 Shimazu ${ }^{\circledR} \mathrm{TOC}-\mathrm{V}$ 总碳分析仪 (精度为 $1.5 \%$ 以 内) 测定, PC 和颗粒有机碳 (POC) 浓度采用 EuroVector ${ }^{\circ}$, EA3000 元素分析仪 (精度为 $0.05 \% \sim 0.15 \%$ ) 测 定. 采集的原水通过 $450^{\circ} \mathrm{C}$ 预燃烧 $4 \mathrm{~h}$ 的 Whatman ${ }^{\odot} \mathrm{GF} / \mathrm{F}$ 膜, 滤液存放于玻璃管中, 加人饱和氯化录溶液于 $0 \sim 4^{\circ} \mathrm{C}$ 低温保存, 用于 DOC 浓度的测定; 所得滤膜一式两份,一份用于 PC 浓度的测定, 另一份用 $1 \mathrm{~mol} / \mathrm{L}$ 的 
盐酸酸化以去除颗粒无机碳 (PIC), 并用蒸馏水清洗 3 次, 用于 POC 浓度的测定. 两份滤膜均烘干至恒重放 于封口袋中, $-20^{\circ} \mathrm{C}$ 冷冻保存, 一周内完成分析. 研究期间, 每月定时在高阳平湖人口和出口采样点采集水 样,测试碳浓度,分别代表河流输人和输出的碳浓度.

由于在高阳平湖水域没有独立的水文站测定水文数据, 以温泉水文站为参考点来推算高阳平湖水域河 流流量值. 温泉水文站控制流域面积为 $1241.1 \mathrm{~km}^{2}$, 而高阳平湖水域控制流域面积约为 $4820 \mathrm{~km}^{2}$. 根据两个 断面的控制流域面积, 即可简单推算出高阳平湖水域的河流流量 ${ }^{[16]}$ :

$$
Q_{1}=3.875 Q_{0}
$$

式中, $Q_{0}$ 为温泉水文站河流流量 $\left(\mathrm{m}^{3} / \mathrm{s}\right)$.

\section{2 水一气界面气体扩散碳通量}

研究将高阳平湖划分为 3 部分, 高阳平湖人口、湖心和出口 3 个采样点数据分布代表这 3 部分的水-气 界面气体扩散通量. 通过公式计算即可估算出水一气界面温室气体 $\left(\mathrm{CO}_{2}\right.$ 和 $\left.\mathrm{CH}_{4}\right)$ 扩散碳通量:

$$
G_{2}=\sum_{j=1}^{3} \frac{3 F_{\operatorname{lux}_{j}} \cdot S_{j} \cdot t}{125}
$$

式中, $G_{2}$ 为水一气界面气体扩散碳通量 $(\mathrm{g}) ; F_{\mathrm{lux}}$ 为各采样点的扩散通量 $\left(\mathrm{mg} /\left(\mathrm{m}^{2} \cdot \mathrm{h}\right)\right) ; S_{j}$ 为各采样点的水域 面积; $j=1 、 2 、 3$ 分别代表高阳平湖人口、湖心和出口采样点.

采用浮箱法监测水一气界面气体扩散碳通量. 研究采用改良型静态箱进行野外监测, 其箱体材料为聚乙 烯塑料, 外观为长方体, 外部有隔热保温包裹. 改良型静态箱三边尺寸为长 $\times$ 宽 $\times$ 高 $=450 \mathrm{~mm} \times 350 \mathrm{~mm} \times 150$ $\mathrm{mm}$, 箱内设有风扇用来混匀气体, 同时还设有感温探头用来测量箱内温度, 每一采样点均设置两个静态箱. 采气全程时间为 $10 \mathrm{~min}$, 采样间隔 $2 \mathrm{~min}$, 每个采样点共取气 6 次. 采样时用针筒抽取静态箱内气体 $100 \mathrm{ml}$, 注人铝笪采气袋后保存, 在 $48 \mathrm{~h}$ 内使用 Agilent GC 7820 气相色谱仪完成气体浓度分析测试, 并通过模型公 式 ${ }^{[17]}$ 计算得到水一气界面气体 $\left(\mathrm{CO}_{2}\right.$ 和 $\left.\mathrm{CH}_{4}\right)$ 扩散碳通量:

$$
F_{\text {lux }}=\frac{k \cdot P \cdot F_{1} \cdot F_{2} \cdot V_{2}}{S P \cdot(273.15+T) \cdot S_{2}}
$$

式中, $k$ 为测试气体浓度变化斜率 $(\mathrm{mg} /(\mathrm{L} \cdot \mathrm{s})) ; P$ 为监测时的大气环境压力 $(\mathrm{kPa}) ; F_{1}$ 为分钟到小时的转换 系数, $60 ; F_{2}$ 为 $\mathrm{ppm}$ 到 $\mu \mathrm{g} / \mathrm{m}^{3}$ 的转换系数; $V_{2}$ 为静态箱内空气体积 $(\mathrm{L}) ; S P$ 为标准大气 $(101.325 \mathrm{kPa}) ; T$ 为 气温 $\left({ }^{\circ} \mathrm{C}\right) ; S_{2}$ 为静态箱所覆盖水面面积 $\left(\mathrm{m}^{2}\right)$.

依据高阳平湖水域水下地形图, 选取 $175 \mathrm{~m}$ 水位线为空间边界面, 以在边界面上到两个采样点间距离 相同点的连线为划分边界, 对整个高阳平湖进行划分. 通过划分后测量计算, 高阳平湖人口、湖心和出口 3 个采样点分别代表了高阳平湖 $22 \% 、 57 \%$ 和 $21 \%$ 的水域面积. 考虑到三峡水库调蓄作用将引起水位的变化, 将高阳平湖水域面积同水位进行回归分析, 即可通过水位高低来推算出高阳平湖水域面积.

\section{3 土一气界面气体扩散碳通量}

受三峡水库调蓄的影响,在夏季低水位运行期,高阳平湖水域会在 $175 \mathrm{~m}$ 水位线以下形成大片近岸消 落带区域. 土壤中含有丰富的有机碳, 土一气界面温室气体的扩散同样也是碳收支路径中重要环节. 通过公 式即可估算出高阳平湖水域近岸消落带土-气界面温室气体扩散碳通量:

$$
G_{3}=\frac{3 F_{\text {lux }} \cdot S_{3} \cdot t}{125}
$$

式中, $G_{3}$ 为土-气界面气体扩散碳通量 $(\mathrm{g})$; $S_{3}$ 为采样月份的消落带面积.

在 2012 年 3-8 月夏季低水位运行期对近岸消落带土-气界面温室气体扩散通量进行监测, 综合考查 后, 采样点选择在高阳平湖水域李家坝处近岸消落带区域. 每月在高阳平湖水域消落带中选取 3 种不同类 型土地性质 (草地、花生地和玉米地) 的采样点, 采用静态箱法, 采样时间均设置在上午 $11: 00$ 左右. 采样提 前 $2 \mathrm{~d}$ 在采样点处埋设静态箱底座, 使其适应周围土壤环境, 采样时采用水封法保证静态箱内密封完全, 每 一采样点均设置两个静态箱. 分别采集 $0 、 10 、 20$ 和 $30 \mathrm{~min}$ 共 4 次样品, 采样时用针筒通过三通阀抽取静态 箱内气体, 注人铝䇴采气袋后保存, 此后处理方法与水-气界面气体相同.

在高阳平湖水域水下地形图中找出 $175 \mathrm{~m}$ 水位线和 $145 \mathrm{~m}$ 水位线之间的消落带区域,选择各个特征边 
坡测量其近岸消落带边坡坡度值, 最后取平均值推算出高阳平湖水域综合边坡坡度值为 $30.9^{\circ}$. 由于已知在 各个水位高度下高阳平湖水域面积, 故通过边坡坡度值即可推算出在各个水位高度下的消落带面积.

\section{4 气泡释放碳通量}

受到三峡水库调蓄的影响, 高阳平湖水域库湾近岸区域呈现出 “落干-淹没” 的交替特征. 野外观测发 现, 自人春开始淹没的库湾近岸区域存在气泡释放现象. 通过公式即可得到高阳平湖水域温室气体气泡释 放碳通量:

$$
G_{4}=\sum_{i=1}^{4} \frac{9}{31250} F_{b i} \cdot S_{i} \cdot t
$$

式中, $G_{4}$ 为气泡释放碳通量 $(\mathrm{g}) ; i=1 、 2 、 3 、 4$ 分别代表深度为 $3 、 5 、 8$ 和 $10 \mathrm{~m}$ 的采样点; $F_{b i}$ 为各采样点气泡释 放通量 $\left(\mu \mathrm{mol} /\left(\mathrm{m}^{2} \cdot \mathrm{d}\right)\right) ; S_{i}$ 为各采样深度所控制的水域面积.

研究时间为 2012 年 3-8 月, 选取高阳平湖水域李家坝处库湾开展气泡监测, 采样周期为每月一次, 均 在当月下旬,每次持续一周. 采样装置采用改进的倒置漏斗, 由金属薄皮材料 (马口铁) 制作, 在接缝处进行 焊接密封, 敞口部为镀锌钢圈包裹在金属薄皮材料内, 其敞口直径为 $750 \mathrm{~mm}$, 高为 $1000 \mathrm{~mm}$, 集气瓶容积为 2 $\mathrm{L}$, 倒置漏斗敞口部分设置有配重 $10 \mathrm{~kg}$ 的吊坠. 水面针绳一端固定于岸边 $175 \mathrm{~m}$ 水位线以上, 另一端固定于 位于库湾湖心的野外实验平台 (平台处水下高程约为 $138 \mathrm{~m}$ ). 4 个气泡收集装置由浅至深地栓于水面针绳 下方, 装置下部敞口处水深约为 $1.5 \mathrm{~m} .4$ 个采样点所在处垂向对应水深分别为 $3 、 5 、 8$ 和 $10 \mathrm{~m}$ (图 4). 随着坝 前水位的变化, 每月开展监测前预先调整 4 个采样点所处水平位置, 确保其所在处对应水深自近岸处至湖 心依次递增. 气泡收集期间, 为避免收集气泡过多而重新溶于水中, 采气时间间隔为 $24 \mathrm{~h}$ 并在现场完成气泡 体积测定. 收集的气体用针筒注人铝䇴采气袋保存, $48 \mathrm{~h}$ 内使用 Agilent GC 7820 气相色谱仪完成气泡气体 浓度分析测试. 气泡释放通量计算公式为:

$$
F_{b i}=\frac{1000 \cdot C_{4} \cdot V_{4}}{S_{4} \cdot t_{1}}
$$

式中, $C_{4}$ 为气泡浓度 $(\mu \mathrm{mol} / \mathrm{L}) ; V_{4}$ 为气泡收集的体积 $\left(\mathrm{m}^{3}\right) ; S_{4}$ 为倒置漏斗底面积 $\left(\mathrm{m}^{2}\right) ; t_{1}$ 为采样间隔时间 (d).

以上 4 个采样点由浅人深将整个高阳平湖湖面看作近似长方形构造, 每个采样点来代表一个深度控制 范围内的气泡释放通量水平,由浅至深依次代表近岸水深 $10 \mathrm{~m}$ 以内湖面 36\%、23\%、23\%和 $18 \%$ 的水域面 积,再结合高阳平湖不同水位时的近岸边坡坡度,即可推算出各月高阳平湖水域温室气体气泡释放通量.

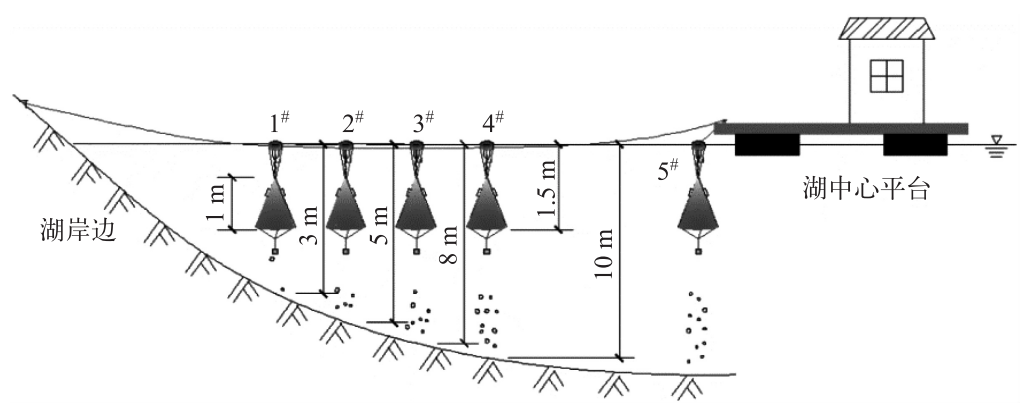

图 4 高阳平湖库湾气泡收集装置布置示意

Fig.4 Sketch of ebullition collecting funnels for collecting bubbles at the sampling estuary of Lake Gaoyang

\section{5 降水输送碳通量}

大气降水过程将会向水生生态环境中输人溶解态无机碳( DIC), 因此降水输送也被看作是高阳平湖水 域碳收支过程的重要路径. 水域面积、降水量和降水碳浓度三者的乘积即为高阳平湖水域降水输送碳通量.

$$
G_{5}=10^{-3} S_{175 \mathrm{~m}} \cdot Q_{5} \cdot C_{5}
$$

式中, $G_{5}$ 为降水输送碳通量 $(\mathrm{g}) ; S_{175 \mathrm{~m}}$ 为水域面积 $\left(\mathrm{m}^{2}\right) ; Q_{5}$ 为采样月份的降雨量 $(\mathrm{mm}) ; C_{5}$ 为降水碳浓度 
$(\mathrm{mg} / \mathrm{L})$.

选取高阳平湖水域 4 次典型短时强降水过程进行研究. 在夏季低水位运行期和冬季高水位运行期各设 置 2 次采样. 每次降水过程前, 高阳平湖水域天气均为多云, 降水结束后天气慢慢转好. 依次在高阳平湖人 口、湖心和出口采集雨水水样, 并同步观测其 $\mathrm{pH}$ 、水温等环境指标. 现场利用塑料采样瓶将采集的雨水水样 混合后, 带回实验室在 $24 \mathrm{~h}$ 内使用 Shimadzu ${ }^{\odot}$ TOC 仪完成其碳浓度的测试, 将 4 次采样结果取平均值即可 得到高阳平湖水域降水输送过程中的水体碳素浓度.

水域面积同样通过模型公式进行推求,空间边界选择为高阳平湖水域 $175 \mathrm{~m}$ 水位线,降水量通过高阳 平湖野外气象站实测得到. 野外气象站设在高阳平湖水域近岸, 定期更换干燥剂和采集数据, 可真实地反映 出高阳平湖水域的各个气象指标.

\section{6 数据处理}

研究期间, 所有数据统一录人 Excel 软件整理分类, 并通过 SPSS 和 Origin 软件进行统计和图形分析, 采 用 Spearman 相关性分析说明数据间变化的线性相关性.

\section{2 结果与分析}

通过对高阳平湖水域主要路径碳收支估算方法的建立, 利用对高阳平湖水域主要碳路径的监测数据, 代人计算公式,即可对高阳平湖水域主要路径的碳收支情况进行估算与分析.

\section{1 河流输送碳通量}

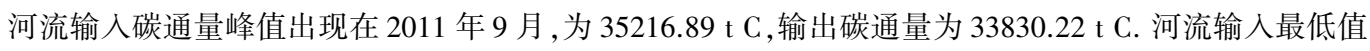
出现在 2012 年 2 月, 仅为 $3110.05 \mathrm{tC}$, 输出碳通量也仅为 $2939.03 \mathrm{t} \mathrm{C.} \mathrm{从} 2011$ 年 12 月至 2012 年 2 月河流输 人和输出的碳通量都处于较低水平, 最高才达到 $4635.86 \mathrm{t} \mathrm{C}$, 且输人和输出变化趋势基本保持一致(图 5). 河流输人碳通量与输出碳通量呈显著正相关关系 $\left(r_{\text {輸入-输出 }}=0.999, S i g . \leqslant 0.01\right)$, 说明河流在输送水体碳素 过程具有连续性. 河流输入碳通量明显大于河流输出碳通量, 这部分差值将滞留在高阳平湖水域中. 从各形 态碳来看, 滞留的 DIC、DOC、POC 和 PIC 的逐月碳通量变化幅度较大, 以 DIC 为主, 仅 DIC 在 2012 年 7 月达 到峰值, 为 $3173.33 \mathrm{tC}, \mathrm{POC}$ 和 PIC 均在 2011 年 9 月达到峰值, 分别为 583.83 和 $537.43 \mathrm{t} \mathrm{C}$ (图 5).

\section{2 水-气界面气体扩散碳通量}

$\mathrm{CO}_{2}$ 扩散通量碳“源” 峰值出现在 2012 年 1 月, 为 $145.41 \mathrm{t}$ C, 而在 2012 年 3 月出现了碳“汇” 的峰值, 为 $-62.72 \mathrm{tC}$, 从 2012 年 5 月之后均表现为碳“汇”, 可能的原因是随着温度逐渐升高, 浮游植物生长旺盛, 光 合作用吸收水体中的 $\mathrm{CO}_{2}$, 使之表现为碳“汇”, 这与蒋滔等 ${ }^{[18]}$ 发现的高阳平湖在低水位期水-气界面 $\mathrm{CO}_{2}$ 的 特征相似. 从 2011 年 9 月至 2012 年 4 月, $\mathrm{CH}_{4}$ 虽表现为碳“源”, 但基本保持较低值, 而在 2012 年 5、6 月, $\mathrm{CH}_{4}$ 扩散通量迅速上升并达到峰值 $(207.27 \mathrm{t} \mathrm{C}$ ), 随后又重新回到较低值. 这可能是由于 $5 、 6$ 月气温回升导 致水温上升, 使得产甲烷菌进人其适宜温度, 促进淹没有机碳被分解从而产生大量 $\mathrm{CH}_{4}$ 扩散通量进人大气 中,随后由于大量有机碳的分解使得水体重新回到平衡( 图 6a).

\section{3 土一气界面气体扩散碳通量}

土一气界面 $\mathrm{CO}_{2}$ 气体扩散通量在 4.5 月表现为碳“汇”, 在 5 月达到峰值, 为 $-45.34 \mathrm{t}$ C. 其余月份 $\mathrm{CO}_{2}$ 气 体扩散通量均表现为碳“源”, 在 6 月达到峰值, 为 $93.01 \mathrm{t}$ C. 土一气界面 $\mathrm{CH}_{4}$ 气体扩散通量在研究期间均处 于较低水平, 大部分时间表现为碳“汇”, 8 月 $\mathrm{CH}_{4}$ 气体通量达到碳“汇” 峰值, 为 $-0.30 \mathrm{t} \mathrm{C}$ (图 6b).

\section{4 气泡释放碳通量}

$\mathrm{CO}_{2}$ 和 $\mathrm{CH}_{4}$ 的气泡释放通量均在 2012 年 6 月迅速上升达到峰值, 此时 $\mathrm{CH}_{4}$ 气泡释放通量为 $0.27 \mathrm{t} \mathrm{C}$, $\mathrm{CO}_{2}$ 为 $0.01 \mathrm{t} \mathrm{C}$, 随后的 $7 、 8$ 月气泡释放量又减小. $\mathrm{CH}_{4}$ 气泡释放通量显著高于 $\mathrm{CO}_{2}$, 且两者释放过程具有同 步性(图 7).

\section{5 降水输送碳通量}

从 2011 年 12 月至 2012 年 2 月大气降水输送碳量都比较低, 且最低值在 2012 年 2 月, 仅为 $0.02 \mathrm{t} \mathrm{C}$; 在 2012 年 7 月突然上升达到峰值, 为 $31.04 \mathrm{t}$ C. 逐月降水输送碳通量变幅较大 (图 8). 

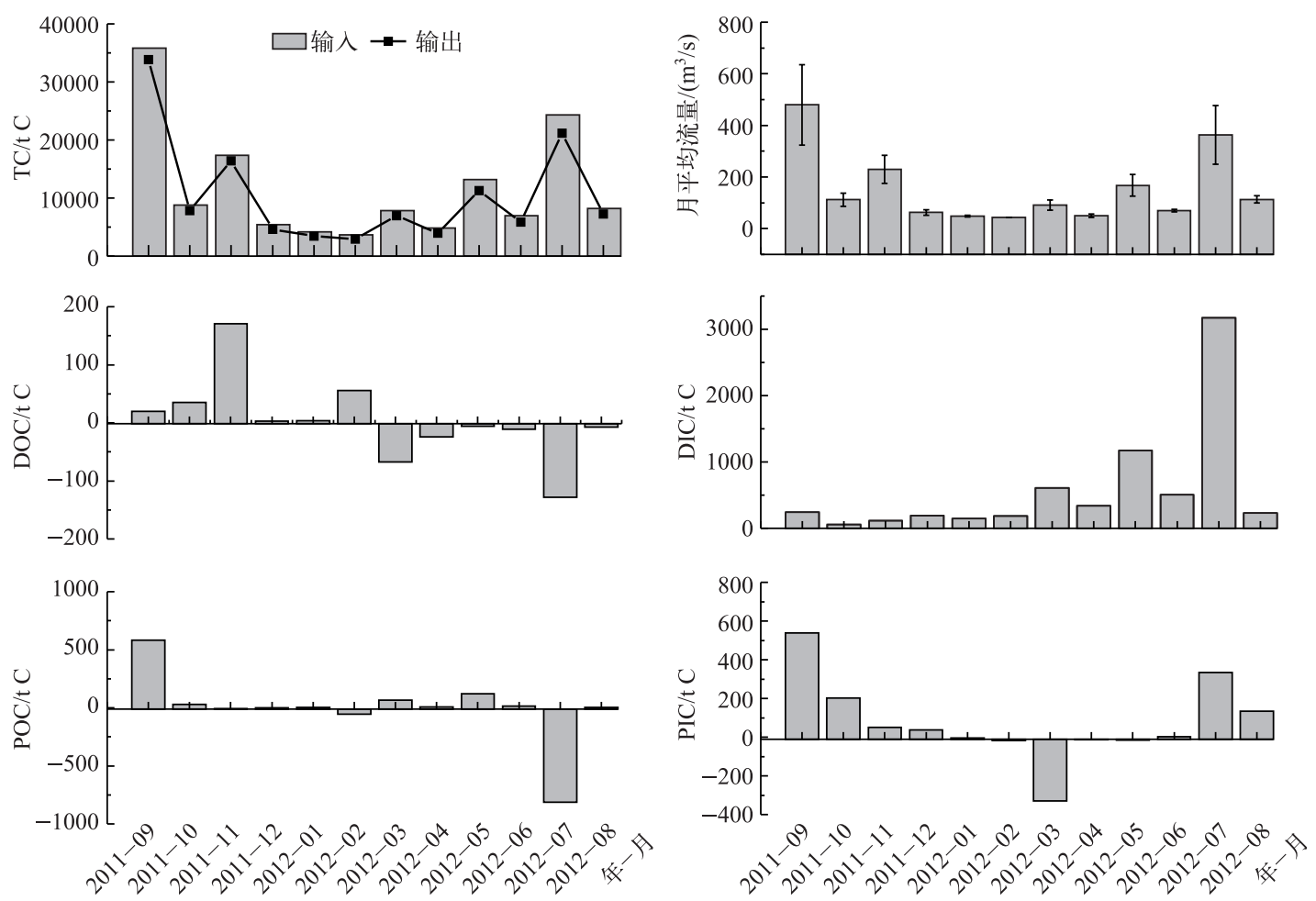

图 5 高阳平湖河流输送总碳、各形态碳通量及河流流量

Fig.5 Carbon budget of river transport, different forms of carbon flux and flow of Lake Gaoyang

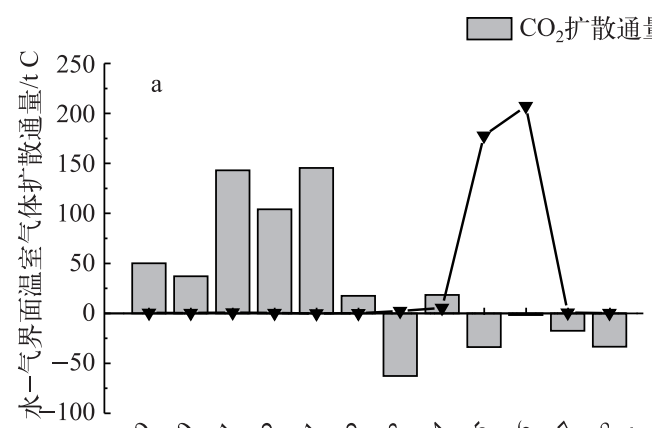

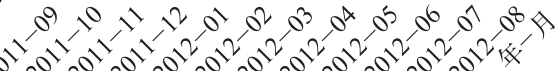

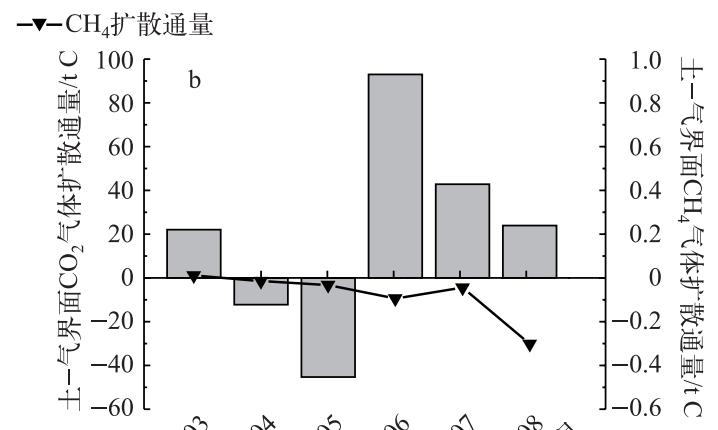

图 6 高阳平湖水一气界面 $(\mathrm{a})$ 和土一气界面 $(\mathrm{b})$ 气体扩散碳通量

Fig.6 Diffusive fluxes of water to air interface (a) and water-level-fluctuating zone (b) of Lake Gaoyang

\section{6 高阳平湖碳积累结果}

对高阳平湖水域 5 个主要路径的碳收支进行逐月估算, 得到一周年高阳平湖水域逐月碳收支情况.

水域整体上呈现出碳积累的特征,从 2011 年 10 月至 2012 年 4 月逐月碳积累都较低,在 1 月出现最低 值, 仅为 $6.83 \mathrm{t}$, 峰值出现在 2012 年 7 月, 为 2572.10 t. 逐月碳积累结果变幅比较明显 (图 9). 


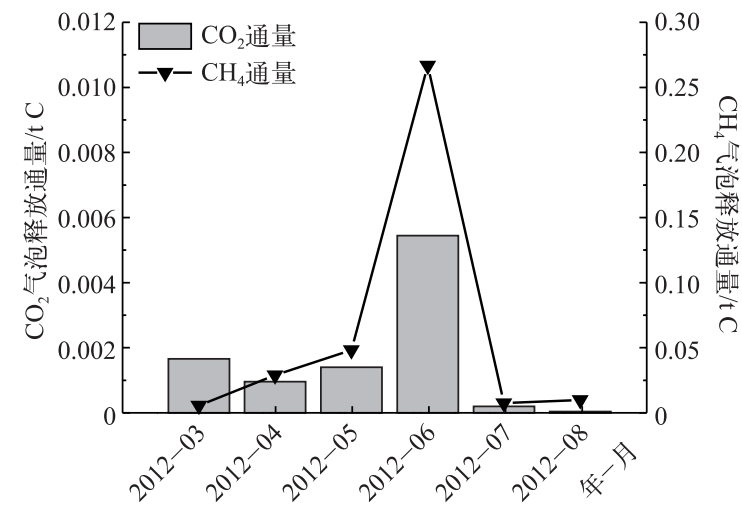

图 7 高阳平湖温室气体气泡释放碳通量

Fig.7 Ebullition fluxes of Lake Gaoyang

\section{3 讨论}

\section{1 高阳平湖水域全年碳通量分析}

对高阳平湖各个路径碳收支情况逐一进行全年核 算(图 10). 河流输人碳通量为 $133548.55 \mathrm{t} \mathrm{C}$, 输出碳通 量为 $125651.82 \mathrm{t} \mathrm{C}$, 全年共有 $7896.73 \mathrm{t} \mathrm{C}$ 在河流输送过 程中滞留在该水域, 其中 DIC 是主要部分, 为 $6979.13 \mathrm{t}$ C. 水-气界面温室气体扩散碳通量整体表现为碳“源”, 全年共有762.56 t C 通过水-气界面从该水域进人大气 中, 其中 $\mathrm{CO}_{2}$ 气体扩散通量为 $366.69 \mathrm{t} \mathrm{C}, \mathrm{CH}_{4}$ 气体扩散 通量为 395.88 t C. 近岸消落带土-气界面温室气体扩 散碳通量整体也表现为碳“源”, 全年共有 123.74 t C 通 过土-气界面从土壤进人大气中, 其中 $\mathrm{CO}_{2}$ 气体排放通量 表现为碳“源”, 为 $124.22 \mathrm{t} \mathrm{C}$, 而 $\mathrm{CH}_{4}$ 气体排放通量尽管 表现为碳“汇”, 但仅为 -0.48 t C. 温室气体气泡释放碳 通量整体亦表现为碳“源”, 但全年也仅有 $0.38 \mathrm{t} \mathrm{C}$ 通过气泡释放的方式从该水域进人大气中, 其中 $\mathrm{CH}_{4}$ 气体 气泡释放通量为 $0.37 \mathrm{t} \mathrm{C}$, 而 $\mathrm{CO}_{2}$ 气体气泡释放通量仅为 $0.01 \mathrm{t} \mathrm{C}$. 全年还有 $104.58 \mathrm{t} \mathrm{C}$ 通过大气降水的方式 输人该水域中.

高阳平湖全年碳输人为 $133653.13 \mathrm{t} \mathrm{C}$, 碳支出为 $126538.50 \mathrm{t} \mathrm{C}$, 全年碳净积累量为 $7114.63 \mathrm{t} \mathrm{C}$, 总体呈 现出碳积累的特征. 碳积累现象主要同河流纵向输移过程中上下游碳的输人输出相关, 这同高阳平湖为过 水型湖泊的生态特征基本吻合.

在高阳平湖水域存在温室气体释放现象, 其中通过水-气界面释放的比重最大, 其次是通过土一气界面, 而气泡释放对碳收支的贡献非常小. 上游大量碳的输人和滞留可能是温室气体释放的来源. 滞留在水域的 碳在合适的情况下促使了 $\mathrm{CO}_{2}$ 和 $\mathrm{CH}_{4}$ 气体释放,使得该水域成为温室气体释放的碳 “源”. 高阳平湖水域源 源不断的碳源输人可能导致温室气体释放现象的持久性存在.

\section{2 不同碳路径的讨论}

三峡水库生态系统碳循环过程在不同的时空区段内呈现明显差别 ${ }^{[19]}$, 高阳平湖水域的碳收支也存在着 时间区段内的差别.

3.2.1 河流输送碳通量 在冬季高水位运行期和泄水期, 河流输人和输出碳通量整体处于较低水平, 且输人 和输出通量基本保持一致; 而在夏季低水位运行期有较高水平的碳通量输送, 且输人碳通量明显大于输出 


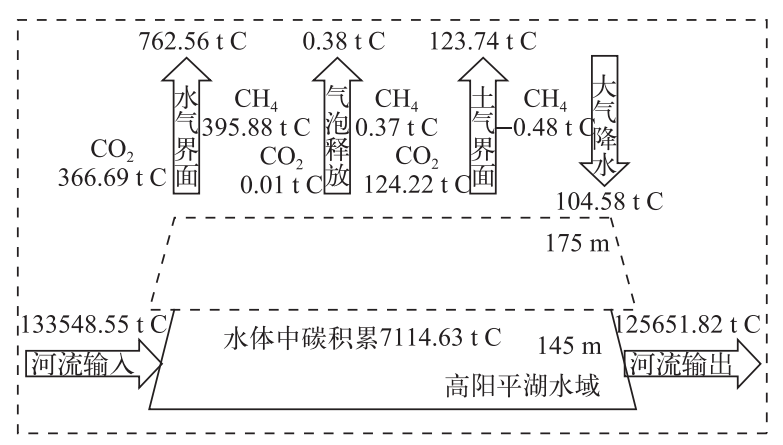

图 10 高阳平湖水域主要路径碳通量收支

Fig.10 The main path of water carbon budget of Lake Gaoyang

碳通量,这部分差值滞留在该水域中. 该水域的上游和下游均为河道型水域,河流在输送过程中由较窄的河 道进人开阔的平湖水域时,流速的减缓可能会使水体携带的碳素在此区域滞留. 夏季低水位运行期,汛期河 流流量较大且使得流速差异较大. 河流流量较大带来了较高的碳通量输送, 流速的差异又使得碳素滞留效 应增大. 而冬季高水位运行期时, 流量大大减小, 流速差异也随之变小, 河流输送碳通量减小, 水域内基本无 碳素滞留现象. 在 2012 年 7 月,河流输送过程中就有 2567.08 t C 滞留在该水域.

3.2.2 水一气界面气体扩散碳通量 研究期间 $\mathrm{CO}_{2}$ 和 $\mathrm{CH}_{4}$ 扩散通量变幅均较大, 冬季高水位运行期 $\mathrm{CO}_{2}$ 气体 扩散通量表现为碳“源” 且保持在较高水平, 而 $\mathrm{CH}_{4}$ 气体扩散通量虽表现为碳“源” 但水平较低, 几乎无变幅; 夏季低水位运行期 $\mathrm{CO}_{2}$ 气体扩散通量在大部分时间中为碳“汇”, 而 $\mathrm{CH}_{4}$ 气体扩散通量表现更为活跃. 不同 水位运行期水-气界面气体扩散通量的这种差异性与环境因素 ( $\mathrm{pH} 、 \mathrm{DO}$ 浓度、水温、叶绿素浓度等) 有关, 具 体参照文献[19].

3.2.3 土一气界面气体扩散碳通量 在泄水期, 土一气界面 $\mathrm{CO}_{2}$ 气体扩散通量整体表现为碳“汇”, $\mathrm{CH}_{4}$ 气体扩 散通量也表现为碳“汇”; 在低水位运行期土一气界面 $\mathrm{CO}_{2}$ 气体扩散通量整体表现为碳“源”, $\mathrm{CH}_{4}$ 气体扩散通 量依旧表现为碳“汇”, 且在 6 月达到碳“源” 的峰值. 从全年来看, 6 月的水位最低, 仅为 $146.94 \mathrm{~m}$, 此时消落 带土壤面积为全年最大值, 且有一部分长时间淹没区在此时露出水面, 沉积的有机碳释放进人大气中, 导致 较高的 $\mathrm{CO}_{2}$ 气体扩散通量. 土一气界面总体对高阳平湖的水域碳收支的贡献较小.

3.2.4 气泡释放气体扩散碳通量 在泄水期, $\mathrm{CO}_{2}$ 和 $\mathrm{CH}_{4}$ 气泡释放通量均表现为碳“源”, 且变幅不大; 在低水 位运行期, $\mathrm{CO}_{2}$ 和 $\mathrm{CH}_{4}$ 气泡释放通量的变幅大, 在 6 月达到峰值, 之后迅速下降为较低水平. 水温升高是导致 气泡形成并释放的根本原因 ${ }^{[20]}$, 气温的上升很可能是 6 月气泡释放通量出现峰值的主要原因, 但 7 月为主 汗期, 水体流动剧烈, 库湾水位陡涨陡落, 故尽管 7 月水温进一步升高, 但水文水动力特征可能不利于气泡 形成并释放,而进人 8 月伏旱期后,径流量下降,为气泡释放创造了稳定的缓流环境 ${ }^{[21-22]}$.

3.2.5 降水输送碳通量降水输送碳通量取决于降水量大小, 在冬季高水位运行期降水量很小, 大气降水输 送碳通量也很小. 随着时间的推移, 降水量的增加也使得大气降水输送相应增加. 7 月为汛期, 降雨量大, 故 大气降水输送碳通量也比较大.

高阳平湖水域逐月碳积累结果受季节和水库运行状态变化影响明显, 在冬季高水位运行期碳积累处于 低水平且变幅小; 泄水期碳积累与高水位运行期相似 (除 5 月变幅较大); 而在夏季低水位运行期,各月碳积 累变幅较大,整体碳通量远高于高水位运行期和泄水期. 5 个不同路径下的碳通量受季节和水库运行状态变 化影响明显导致整个水域碳通量变化明显.

\section{3 高阳平湖碳收支的局限性和不确定性分析}

本研究以宏观介质界面 (水-气界面、土一气界面) 和空间界面 (控制断面) 获得了一个完整周年内高阳 平湖的碳通量收支情况. 尽管总体上高阳平湖全年呈现出碳积累的特点, 但一些方法依然存在局限性或不 确定性：

1) 对高阳平湖出人口的大断面测量依赖于每月 1 次的监测采样,监测结果的瞬变性及其代表性对研究 
结果将可能产生显著的影响.

2) 水-气界面 $\mathrm{CO}_{2}$ 和 $\mathrm{CH}_{4}$ 扩散通量,易受到现场风速、气压、温度改变等气象条件的干扰,具有时空异质 性特点. 静态箱法通过测量箱体内气体浓度变化的方法获得水一气界面 $\mathrm{CO}_{2}$ 和 $\mathrm{CH}_{4}$ 气体扩散通量, 虽然该方 法被广为采用, 但它将在一定程度上改变现场的实际环境条件, 将可能使得水一气界面 $\mathrm{CO}_{2}$ 和 $\mathrm{CH}_{4}$ 扩散通量 的测试值同实际情况之间存在偏差,从而使得测试结果具有不确定性.

3) 同水-气界面扩散碳通量相似,气泡释放碳通量亦具有极强的时空异质性. 通常认为气泡产生同水 温、水深、流速、湖底有机质含量等密切相关, 但在监测中并无法准确判定气泡释放空间和时间特点. 故监测 结果本身亦具有一定不确定性.

4) 高阳平湖的分层及季节变化会对 $\mathrm{CO}_{2}$ 和 $\mathrm{CH}_{4}$ 水平迁移产生影响, 深水水库温跃层以下的 $\mathrm{CO}_{2}$ 和 $\mathrm{CH}_{4}$ 可能在扩散到表层之前, 就通过河流输送到下游载释放出来,这个量可能很多,但在水一气界面通量上反映 不出来.

除上述方法可能存在的不确定性外, 在进行碳通量的计量中, 不同方法之间的监测误差和不确定性传 递问题在本研究中并未予以考虑. 上述方法的局限性或不确定性, 使得本研究结论依然需要更系统、更长期 工作予以验证或改进.

\section{4 参考文献}

[ 1 ] Meybeck M. Carbon, nitrogen, and phosphorus transport by world rivers. American Journal of Science, 1982, 282(4) : 401-405.

[ 2 ] Ittekkot V. Global trends in the nature of organic matter in river suspensions. Nature, 1988, 332(6163) : 436-438.

[ 3 ] Schlesinger WH, Melack JM. Transport of organic carbon in the world's rivers. Tellus, 1981, 33(2) : 172-187.

[ 4 ] Yu Guirui, Fang Huajun, Fu Yuling et al. Research on carbon budget and carbon cycle of terrestrial ecosystems in regional scale: A review. Acta Ecologica Sinica, 2011, 31(19): 5449-5459. [于贵瑞, 方华军, 伏玉玲等. 区域尺度陆地生态 系统碳收支及其循环过程研究进展. 生态学报, 2011, 31(19) : 5449-5459.]

[ 5 ] Sun Wei, Wu Rihan. The carbon balance and its spatial differentiation of the Yangtze River delta. Geographical Research, 2012, 31(12) : 2220-2228. [ 孙伟, 乌日汗. 长三角核心区碳收支平衡及其空间分异. 地理研究, 2012, 31( 12)： 2220-2228. ]

[ 6 ] Ran Jingjiang, Lin Chuxue, Guo Jinsong et al. Reservoir greenhouse effect research progress and main influence factors analysis. Resources and Environment in the Yangtze Basin, 2011, 20(2) : 197-202. [曲景江, 林初学, 郭劲松等. 水库温 室效应研究进展与主要影响因素分析. 长江流域资源与环境, 2011, 20(2)：197-202.]

[ 7 ] Chen Jin, Huang Wei. Greenhouse gas emission of reservoir. Journal of Yangtze River Scientific Research Institute, 2009, 25(6) : 1-5. [ 陈进, 黄薇. 水库温室气体排放问题初探. 长江科学院院报, 2009, 25(6) : 1-5. ]

[ 8 ] Hope D, Kratz TK, Riera JL. Relationship between $\mathrm{pCO}_{2}$ and dissolved organic carbon in northern Wisconsin lakes. Journal of Environmental Quality, 1996, 25(6) : 1442-1445.

[ 9 ] Richey JE, Wissmar RC, Devol AH et al. Carbon flow in four lake ecosystems: A structural approach. Science, 1978, 202 (4373) : 1183-1186.

[10] Richey JE, Hedges JI, Devol AH et al. Biogeochemistry of carbon in the Amazon River. Limnology and Oceanography, 1990, 35(2) : 352-371.

[11] Keller M, Stallard RF. Methane emission by bubbling from Gatun Lake, Panama. Journal of Geophysical Research, 1994, 99( D4) : 8307-8319.

[12] Duchemin E, Lucotte M, Canuel R et al. Production of the greenhouse gases $\mathrm{CH}_{4}$ and $\mathrm{CO}_{2}$ by hydroelectric reservoirs of the boreal region. Global Biogeochemical Cycles, 1995, 9(4) : 529-540.

[13] Ji Xiaoyan, Cui Guangbo, Yang Longyuan et al. Measurement of the $\mathrm{CO}_{2}$ flux on the water-air interface of Taihu Lake. Environmental Science, 2006, 27(8): 1479-1486. [嵇晓燕, 崔广柏, 杨龙元等. 太湖水-气界面 $\mathrm{CO}_{2}$ 交换通量观测研 究. 环境科学, 2006, 27(8): 1479-1486.]

[14] Li Z, Zhang Z, Xiao Y et al. Spatio-temporal variations of carbon dioxide and its gross emission regulated by artificial operation in a typical hydropower reservoir in China. Environ Monit Assess, 2014, 186(5) : 3023-3039. 
[15] López-Tarazón JA, López P, Lobera G et al. Suspended sediment, carbon and nitrogen transport in a regulated Pyrenean river. Science of the Total Environment, 2015, 540: 133-143.

[16] Li Zhe. The research of habitat transition and phytoplankton succession in the Xiaojiang river backwater area during the preliminary operation of the Three Gorges Reservoir [ Dissertation]. Chongqing: Chongqing University, 2009. [李哲. 三峡 水库运行初期小江回水区藻类生境变化与群落演替特征研究 [学位论文]. 重庆: 重庆大学, 2009.]

[17] Lambert M, Fréchette JL. Analytical techniques for measuring fluxes of $\mathrm{CO}_{2}$ and $\mathrm{CH}_{4}$ from hydroelectric reservoirs and natural water bodies. In: Therrien AJ ed. GHG emissions from boreal reservoirs and natural aquatic ecosystems, in greenhouse gas emissions-fluxes and processes. Berlin: Springer Berlin Heidelberg, 2005 : 37-60.

[18] Jiang Tao, Guo Jinsong, Li Zhe et al. Air-water surface greenhouse gas flux in Pengxi river at different operational stages of the Three Gores Reservoir. Environmental Science, 2012, 33(5): 1463-1470. [蒋滔, 郭劲松, 李哲等. 三峡水库不同 运行状态下支流澎溪河水-气界面温室气体通量特征初探. 环境科学, 2012, 33(5): 1463-1470.]

[19] Lu F, Yang L, Wang XK et al. Preliminary report on methane emissions from the three gorges reservoir in the summer drainage period. Journal of Environmental Sciences, 2011, 23(12) : 2029-2033.

[20] Duchemin E, Lucotte M, Canuel R et al. Comparison of greenhouse gas emissions from an old tropical reservoir with those from other reservoirs worldwide. Verhandlungen der Internationalen Vereinigung fiur Theoretische und Angewandte Limnologie, 2000, 27 : 1391-1395.

[21] Li Zhe, Zhang Cheng, Liu Liang et al. Ebullition flues of $\mathrm{CO}_{2}$ and $\mathrm{CH}_{4}$ in Pengxi river, Three Gorges Reservoir. J Lake Sci, 2014, 26(5) : 789-798. DOI: 10.18307/2014.0518. [李哲, 张呈, 刘啨等. 三峡水库澎溪河 $\mathrm{CO}_{2} 、 \mathrm{CH}_{4}$ 气泡释放 通量初探. 湖泊科学, 2014, 26(5) : 789-798.]

[22] Li Zhe, Guo Jinsong, Fang Fang et al. 1D hydrodynamic model on Pengxi (Xiaojiang) river backwater area in the Three Gorges Reservoir. Journal of Chognqing University, 2012, 35(5)：143-150. [李哲, 郭劲松, 方芳等. 三峡澎溪河( 小 江) 回水区一维水动力特征研究. 重庆大学学报: 自然科学版, 2012, 35(5) : 143-150.] 